Erratum

\title{
The endocrine basis
}

for developmentally stationary prepupae in larvae of Trichoplusia ni pseudoparasitized by Chelonus insularis

Davy Jones

Department of Entomology, University of Kentucky, Lexington, Kentucky 40546-0091, USA

J Comp Physiol B (1985) 155:235-240

Due to an unfortunate error, the final sentence of the legend to Fig. 2 was omitted. This would have read: Hemolymph ecdysteroid concentration is $\times 1 / 7$.

Also, the reference Jones and Sreekrishna (1984) should have read as follows:

Jones D, Sreekrishna S (1984) Precocious metamorphosis in Chelonus parasitized Trichoplusia ni: The endocrine basis for this anti-juvenile hormone effect. In: Borkovec $A B$, Thomas TJ (eds) Insect neurochemistry and neurophysiology. Plenum Press, New York, pp 389-391 